Article

\title{
Assessing Blockchain Investments through the Learning Option: An Application to the Automotive and Aerospace Industry
}

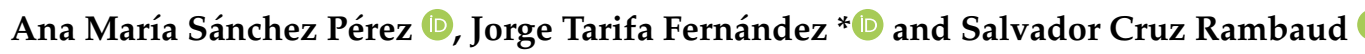 \\ Department of Economics and Business, University of Almería, 04120 Almería, Spain; \\ amsanchez@ual.es (A.M.S.P.); scruz@ual.es (S.C.R.) \\ * Correspondence: jorgetarifa@ual.es; Tel.: +34-950-214-165
}

Received: 29 November 2020; Accepted: 11 December 2020; Published: 14 December 2020

\begin{abstract}
Blockchain technology has demonstrated huge potential in providing simplicity and efficiency for different industries. However, its implementation in the automotive and aerospace industry is quite slow because of its difficulty to show value creation. Real option methodology, specifically the learning option, is an assessment tool which fits the conditions under which investment in blockchain technology is carried out. Thus, its application can help managers to wisely invest in this technology despite the complexity of this industry. This study offers a suitable tool to assess the strategic value of an investment in blockchain technology from a conservative position by using the real option approach, particularly the learning option. Specifically, this paper provides the mathematical expression to obtain the value of a project which includes the learning option for $n$ periods. Likewise, it tries to raise awareness among managers of the importance to gather relevant information before making irreversible decisions. The results show that, despite the high profitability of the analyzed sector and the strategic value added by the learning option to the investment, the value of this option remains constant over the project lifespan. This indicates that the blockchain investment has to be implemented as soon as possible given that it is a highly profitable project whose value increases very slowly by waiting to get more new information. In this way, the immediate investment in blockchain technology in the automotive and aerospace industry is recommended to reap the competitive advantages offered by digital technologies.
\end{abstract}

Keywords: blockchain technology; real options; automotive and aerospace industry; learning option

\section{Introduction}

Recently, digital technologies have become an increasingly common part of the business reality. Despite their high uncertainty, these technologies have not taken a long time to settle down, leading firms to adopt them if they want to create a higher added value and, therefore, remain competitive $[1,2]$. This situation has become the ideal breeding ground for the blockchain technology to stand out as it has the ability to generate new opportunities related to the information treatment and to offer several possibilities to solve some specific problems [3]. For instance, because of its hash function, no transaction can be modified; instead, a different operation is generated in order to complete the information described by the previous one [4]. This has transformed the way in which firms relate to each other, thus changing the rules of behavior in collaborative relationships.

These changes inherently imply higher levels of uncertainty, which are translated into a prudent valuation of investments in digital technologies. In this way, real options have been considered as an excellent tool when estimating and anticipating future trends [5]. In effect, real options have been the methodology commonly used in the existing literature to assess the projects consisting of adoption 
or acquisition of technology [6-8]. Real options involve, for a given period, the possibility to take future decisions on real investments without committing oneself in advance [9]. They can be defined as the right, but not the obligation, to take future strategies (e.g., to defer, expand, abandon, or learn). In this way, real options "assess the management's ability to wait and to revise the initial operating strategy if future events turn out to be different from originally predicted" [10]. This instrument allows managers to add strategic value to firms and helps them to make more informed decisions in the future. Therefore, an option-based approach is a representation of the decision process as managers can decide to invest in digital technologies or just to wait until a more favorable scenario [10-12].

Therefore, real options would be of great help in valuing certain investments in digital business transformation, even more so in complex environments such as the automotive and aerospace industry where uncertainty is extremely high [13]. This, together with the intricate and continuously changing structure of this industry, makes investing in blockchain technology critical [14]. As a solution, real options can capture the uncertainty, the future of the industry, and the irreversibility of the investment decision by firms [15]. Under these circumstances, the learning option is the one which best adapts to this context because it allows managers to make an initial investment and wait for new information to continue (or not) the investment. That is to say, it is a matter of not making a substantial investment at the beginning but making small investments and taking the appropriate decisions once there is more reliable information.

In the absence of simple and useful tools to assess the real options, managers demand basic models (such as the net present value (NPV)) that are able to evaluate projects that have the possibility of modifying their strategies. Considering that the learning option has been scarcely studied previously, this paper focuses on developing a familiar expression, according to the nomenclature used in the NPV formula and the employment of the binomial model, to assess the learning option. With the purpose of bridging the gap between the theory and the practice in real options, this paper provides a useful and handily tool to assess the learning option in real business, as well as its practical implementation. Specifically, the value of investing in a disruptive technology such as blockchain was assessed in the automotive and aerospace industry, which involves a high uncertainty.

In this sense, given that the real option's implementation relevance is directly related to the project uncertainty, this paper aims to advance the knowledge about the assessment of investment in blockchain technology by applying a real option tool. In doing so, it pretends to capture the strategic value of the investment project, facilitating the decision-making process in high-uncertainty industries such as the automotive and aerospace industry. The main contribution of this work is twofold. On the one hand, it offers an adequate tool to assess the strategic value of the investment in blockchain technology from a conservative perspective. On the other hand, it highlights the importance of acting timely when considering the implementation of the blockchain technology, without reducing profitability.

The rest of this paper is structured as follows: Section 2 highlights the importance of the blockchain technology within the automotive and aerospace industry. Section 3 derives the formulas for the option to learn, including its casuistry and particularities. In Section 4, the formulas obtained in the former section are applied to the data coming from this industry, by obtaining the value of the option. Lastly, Section 5 concludes the paper providing the main conclusions and implications and a discussion for further research.

\section{The Blockchain Technology and the Automotive and Aerospace Industry}

The use of blockchain technology has been demonstrated to have a positive impact on firm management. Thus, firms have experimented with certain improvements such as an increase in transparency, shortening of the validation of transaction, or elimination of diverse types of risks [16-18]. These improvements are of great importance in the automotive and aerospace industry as blockchain technology acts on payments, insurance, and the management of the supply chain $[19,20]$. Therefore, due to the high connectivity which characterizes interorganizational relationships in this industry, the smallest technological change triggers considerable digital threats. In this way, the protection of 
these processes turns blockchain technology into the primary tool for the development of this industry, moving it toward new, agile, and networked business processes. Firms need to educate themselves and assess the impact of blockchain to determine its value [21]. Thus, blockchain has been considered as one of the digital technologies with great potential to support greater growth and efficiency in the automotive and aerospace industry [22].

According to Aaronson et al. [23], blockchain can create value for the industry through three main points: (a) unlocking business efficiencies, (b) disintermediating suppliers, and (c) enabling new business and customer offerings. The first is the consequence of creating a record of what happens at each step of a process, making that record permanently accessible. This is of interest when trying to determine the location and availability of different parts. At the end, this record becomes an instruction manual where it can be drawn upon when any problem or doubt arises, while also becoming a reference for future supplies and a source of learning and continuous improvement. The second especially focuses on suppliers in the middle of the value chain. This can be of particular interest for suppliers working with early-stage materials because it allows having more excellent knowledge about the phases currently carried out by intermediaries. This disintermediation redistributes value, pooling it at either end. The third allows firms to create products and services which were not possible before. Thus, manufacturers can ensure that not only the correct version of a part is printed but also the authorized number of copies, eliminating the risk of versioning errors.

According to The Boston Consulting Group (BCG) and Accenture Consulting reports [23,24], on the one hand, blockchain has been positioned as one of the best digital technologies with potential to support greater growth and efficiency in the automotive and/or aerospace industry. On the other hand, they highlighted the current moment as the one to learn and prepare because of two main reasons: (a) blockchain technology is real but still maturing, and (b) blockchain is a component, a first step of what will be a transformation, but not the transformation itself.

Specifically, it has been considered that the learning option would better fit the assessment of the investment in blockchain technology due to three main reasons. Firstly, it is a more dynamic option in comparison to others (e.g., the option to defer), by allowing some room for maneuvers and helping to break down barriers when adopting major digital changes, which is in line with the preparation for a digital transformation. Secondly, it allows learning from changes in the environment and waiting for the best moment, which enables adapting perfectly to the managerial process [10]. Thirdly, it helps managers or general directors to address the initial changes for digital transformation as they can also articulate the investment in other complementary digital technologies able to boost the expected benefits.

For that reason, firms within the automotive and aerospace industry, which are always on the lookout for capabilities, technologies, and tools which allow them to optimize performance [25], have to be updated on the development of blockchain, as this technology is rapidly evolving.

\section{Investing While Discovering: The Learning Option}

According to Adner and Levinthal [26], if an investment project has a high level of sunk cost and is highly connected to the uncertainty factor, the real option model should be applied. In addition, the possibility to delay the initial investment in a project allows for obtaining more information and, therefore, its inclusion in the decision-making process. In delayed decisions, active and passive learning reduces the uncertainty, thus improving decisions. When managers expect a reduction in uncertainty, the learning is passive (mainly approached by the option to defer). However, learning is active when it includes a formal investment to gain information and reduce uncertainty (mainly approached by the option to learn). When managers face decisions of special relevance or with a high expected impact, managers rarely wait. They usual carry out the necessary actions to either affect changes or obtain more information [27].

This paper is focused on the aerospace and automotive industry, a sector where research and development play a very significant role, thus involving a high uncertainty. This, combined with the 
fact that the implementation of the new and revolutionary blockchain technology is being analyzed, makes it necessary that the assessment of this project is done by applying real options in order to capture its strategic value.

The next step is to choose the real option which best fits this project by considering its special casuistry. In effect, when facing the opportunity of investing in a new project, managers have different options: to invest at the present moment, to wait a time period and to invest in the future, or to not invest. Considering the current relevance of the investment in blockchain (a technology which implies crucial changes in the decentralization, quickness, and globalization), managers should not close the doors to investment (if not done at the present moment, then after waiting in order to obtain more information). This allows considering the learning option or the deferment option (which implies passive learning). In this context, when assessing investment in a new technology with uncertain benefits, there is a strong incentive to adopt some form of active information before taking the final decision [28,29].

A way to obtain quality information before making a final, often irreversible, investment decision is through a learning option [27]. In this way, the payment of an initial investment, before undertaking the actual project, may reduce the market uncertainty by learning about it. Generally, learning options appear when a firm can speed up the arrival of valuable information by investing [30]. However, it is compulsory that the expected information has the ability to modify future investment decisions [31]. Thus, the learning option gives managerial flexibility, which may prevent significant losses or may indicate a significant potential profit [32]. As with the other real options, the learning option is applied in the decision-making process when facing an investment opportunity. The initial investment to carry out the option may range from a simple survey to market research to the development of a small prototype, the initial adoption of a technology, or the application on a limited area, instead of covering the whole territory.

The learning option is one of the less studied options in practice. Only a small number of researches explicitly analyzed the learning component in the real option approach. Initially, Copeland and Keenan [31] brought to light that the learning option is only worthwhile when the information to be discovered has a significant value. In Child and Triantis [33], the decision of investment in research and development (R\&D) was analyzed from a learning context by the collateral learning between different projects. In this way, Krychowski and Queling [30] showed an example where the learning option captures the central aspect of the "scale dilemma" in the deployment of new technology. Likewise, Martzoukos [27] claimed that investment to learn, even with a negative expected outcome, may add value to the investment opportunity because "the potential for information revelation, captured through the volatility of the control, enhances the value of the underlying investment option" (p. 321).

It is remarkable that the learning option plays a more important role in the case of technologies which are shrouded in significant uncertainty regarding outcomes [29,34]. The learning option is typical for new products or disruptive technologies (e.g., Internet of things, blockchain, and artificial intelligence) in early stages, given that less is known about their new markets. This is the reason why the learning option becomes the more useful approach to assess a blockchain project in the context of the automotive and aerospace industry.

\subsection{Nomenclature}

Table 1 provides the notation employed in this paper.

Table 1. List of notations (source: own elaboration).

\begin{tabular}{cc}
\hline Symbol & Description \\
\hline$V(L)_{0}$ & Present value of the project with the learning option \\
$I_{L}$ & Investment necessary to carry out the learning option at the present moment \\
$I_{0}$ & Investment necessary to carry out the project at the present moment \\
$I_{T}$ & Total investment (valued at the present moment), i.e., $I_{T}=I_{L}+I_{0}$ \\
\hline
\end{tabular}


Table 1. Cont.

\begin{tabular}{cc}
\hline Symbol & Description \\
\hline$V_{k}$ & Value of future cash flows at moment $k$ \\
$r_{f}$ & Probability density function of the value of the future cash flows \\
$u$ & Risk-free interest rate \\
$d$ & Upper factor of cash-flow fluctuation \\
$V^{+}$ & Lower factor of cash-flow fluctuation \\
$V^{-}$ & Project value at moment $k+1$ in the favorable scenario \\
$p$ & Project value at moment $k+1$ in the unfavorable scenario \\
$q$ & Probability of occurrence of the favorable scenario \\
$\sigma$ & Probability of occurrence of the unfavorable scenario \\
$x$ & Project volatility \\
$x_{\max }$ & Porcentage increment of the present value of the future cash flows $\left(V_{0}\right)$ as a \\
$\alpha$ & Consequence of investing in the learning option (see Appendix A) \\
$n$ & Correcting factor, calculated as follows : $\alpha=\left(x_{\text {max }}-1\right)-\frac{I_{L} \cdot x_{\max }}{V_{0}}$ \\
$m$ & Time horizon of the option to learn
\end{tabular}

\subsection{Valuing the Learning Investment}

When deciding on investment in learning, firms must contrast the value of the option with its cost [31]. The "investment" in learning is worthy as long as the value of the project with flexibility, minus the cost of flexibility (in this case, the investment in learning), is higher than the value of the project without flexibility [30].

The development of simple models to assess the learning option acquires particular relevance as, most of the time, they are not easy to understand for managers, given that the comfortable and knowledgeable use of some models requires advanced mathematical skills [10]. In this sense, some papers, e.g., Plaza-González and Sánchez-Pérez [35] and Cruz-Rambaud and Sánchez-Pérez [36], analyzed the value of the project through real options from different points of view, by employing the binomial model, given its simplicity and usability.

In order to assess the value of a project, the methodology employed in this paper is the multiplicative binomial model specifically applied to learning options. In the next few paragraphs, the process to obtain the expression to calculate the value of a project with the learning option is explained in detail.

First of all, the mathematical expression of the present value of a project with the option to learn within $n$ years (denoted by $\left.V(L)_{0}^{n}\right)$, by using a continuous stochastic process, is the following:

$$
V(L)_{0}^{n}=\frac{1}{\left(1+r_{f}\right)^{n}} \int_{-\infty}^{+\infty} \max \left\{x V_{n}-I_{T}\left(1+r_{f}\right)^{n}, 0\right\} f\left(V_{n}\right) \mathrm{d} V_{n} .
$$

Next, the fundamentals of the so-called binomial model are briefly explained. This methodology is based on the assumption that the project value depends on the fluctuations of the future cash flow, at instant $k+1$, starting from its value at instant $k, V_{k}: u V_{k}$ and $d V_{k}$, where $u>1$ and $0<d<1$.

Figure 1 displays the stochastic process corresponding to the time period $[k, k+1]$. In this way, the project value depends on the movement of the future cash flow upward or downward, which gives the project value in the best and worst scenarios, $V^{+}$or $V^{-}$, respectively, as follows:

$$
\begin{aligned}
& V^{+}=\max \left\{x u V_{0}-I_{T}\left(1+r_{f}\right)^{n}, 0\right\}, \text { with probability } p . \\
& V^{+}=\max \left\{x d V_{0}-I_{T}\left(1+r_{f}\right)^{n}, 0\right\}, \text { with probability } q .
\end{aligned}
$$




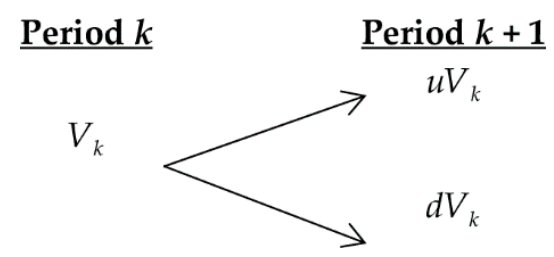

Figure 1. Evolution of the future cash flow from period $k$ to period $k+1$ using the binomial model (source: own elaboration).

In the binomial model, $V^{+}$and $V^{-}$are simplified representations that range within infinite possible values depending on how $V_{k}$ fluctuates in the future. Specifically, $V^{+}$represents the possible values above the current value, and $V^{-}$represents the possible values below.

Finally, to obtain the general expression of the project with the learning option within a period, it is necessary to calculate the following expression:

$$
V(L)_{0}^{1}=\frac{p V^{+}+q V^{-}}{1+r_{f}}
$$

where $p=\frac{\left(1+r_{f}\right)-d}{u-d}$ and $q=1-p=\frac{u-\left(1+r_{f}\right)}{u-d}$.

Subsequently, the result of substituting Equations (1) and (2) into Equation (3) is the following formula that allows calculating the value of a project with the learning option, within a period:

$$
V(L)_{0}^{1}= \begin{cases}x V_{0}-I_{T}, & \text { if } I_{T}<\frac{d^{n} V_{0}}{\left(1+r_{f}\right)} \\ p\left(\frac{u x V_{0}}{\left(1+r_{f}\right)}-I_{0}\right), & \text { if } \frac{d V_{0}}{\left(1+r_{f}\right)} \leq I_{T}<\frac{u V_{0}}{\left(1+r_{f}\right)} \\ 0, & \text { if } \frac{u^{n} V_{0}}{\left(1+r_{f}\right)} \leq I_{T}\end{cases}
$$

In order to derive a unique expression to obtain the value of the learning option within $n$ periods, using the binomial option pricing model, Figure 2 shows the evolution of the value of future cash flows for $n$ periods.

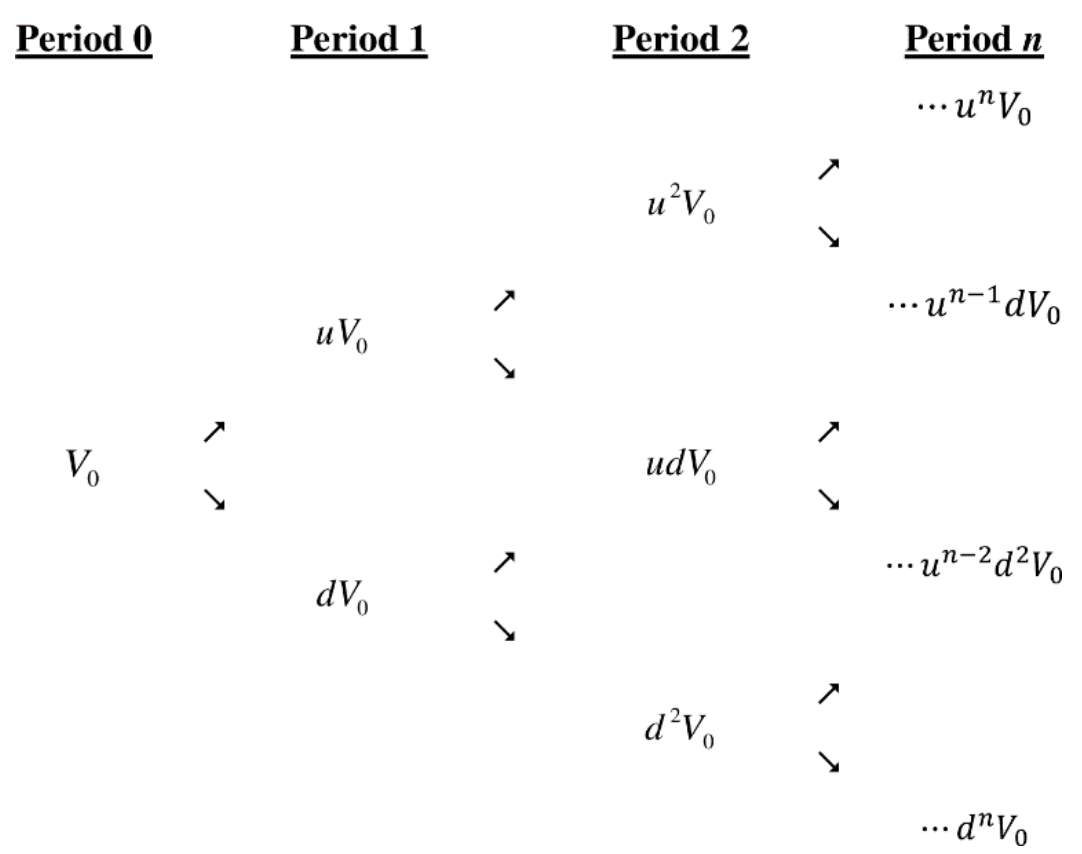

Figure 2. Evolution of the project value in $n$ periods following the binomial model (source: own elaboration). 
In general, the probability of $u^{n-s} d^{s} V_{0}$ is $\left(\begin{array}{c}n \\ s\end{array}\right) p^{n-s} q^{s}$, where $s=1,2, \ldots, n$. Now, the next $n+2$ possible intervals for $I_{T}$ can be considered as follows:

- $\quad I_{T}<\frac{d^{n} V_{0}}{\left(1+r_{f}\right)^{n}}$,

- $\frac{d^{n-s+1} u^{s-1} V_{0}}{\left(1+r_{f}\right)^{n}} \leq I_{T}<\frac{d^{n-s} u^{s} V_{0}}{\left(1+r_{f}\right)^{n}}$

- $\frac{u^{n} V_{0}}{\left(1+r_{f}\right)^{n}} \leq I_{T}$.

Observe that all these intervals are consecutive and disjointed and have increasing left and right endpoints. Moreover, as $d<u$, they are well defined. In this way, the expression to obtain the value of the project with the learning option within $n$ periods, denoted by $V(L)_{0}^{n}$, is the following:

$$
V(L)_{0}^{n}=\left\{\begin{array}{lcl}
x V_{0}-I_{T}, & \text { if } & I_{T}<\frac{d^{n} V_{0}}{\left(1+r_{f}\right)^{n}} \\
\vdots & \vdots & \\
\sum_{k=s}^{n}\left(\begin{array}{l}
n \\
k
\end{array}\right) p^{k} q^{n-k}\left(\frac{u^{k} d^{n-k} x V_{0}}{\left(1+r_{f}\right)^{n}}-I_{0}\right), & \text { if } & \frac{d^{n-s+1} u^{s-1} V_{0}}{\left(1+r_{f}\right)^{n}} \leq I_{T}<\frac{d^{n-s} u^{s} V_{0}}{\left(1+r_{f}\right)^{n}} \\
\vdots & \vdots & \\
0, & \text { if } \frac{u^{n} V_{0}}{\left(1+r_{f}\right)^{n}} \leq I_{T}
\end{array} .\right.
$$

Below, each particular expression of Equation (4) is explained.

- In the first interval, $I_{T}<\frac{d^{n} V_{0}}{\left(1+r_{f}\right)^{n}}$, the value of the initial investment is lower than the project value in the worst scenario (it is multiplied by the factor $d$ ), discounted until moment 0 . In this way, it is advisable to invest in the project. Specifically, the project value is given by the difference between the incremented present value of the future cash flows, $x V_{0}$, as a consequence of investing in the option to learn and the total investment (the initial investment to carry out the project and the investment to carry out the learning option).

- In the second interval, $\frac{d^{n-s+1} u^{s-1} V_{0}}{\left(1+r_{f}\right)^{n}} \leq I_{T}<\frac{d^{n-s} u^{s} V_{0}}{\left(1+r_{f}\right)^{n}}$, the value of the initial total investment is in an intermediate position between the present value of the cash flow in the less favorable situation and in the most favorable one.

- In the last interval, $\frac{u^{n} V_{0}}{\left(1+r_{f}\right)^{n}} \leq I_{T}$, the initial investment is higher than the present value of the cash flow in the best scenario; thus, it is not recommended to carry out the investment.

\section{Application of the Option and Main Results}

In this section, the aim is to analyze the learning option in an aggregate way, by applying real data of the investment in blockchain technology to the automotive and aerospace industry. Despite the application of real options being more typical when assessing individual projects, some previous studies, e.g., Sarkar [37], claimed that real options may be extended to aggregate investments. Moreover, Dikos [38] tested and accepted the real option approach with aggregate data. In the same way, Sahaym et al. [39] studied the aggregated data of the United States (US) manufacturing industry from a real option perspective.

The analysis was based on data from the report "Blockchain in Automotive and Aerospace and Aviation Market: Focus on Key Application and Types of Blockchain-Analysis and Forecast, 2019-2029" published in 2019 by BIS Research [40], which contains information about more than 150 companies across the value chain of the automotive and aerospace industry. The report focuses on the major driving forces, challenges, and growth opportunities in the market. The major players were identified on the basis of revenue generation with respect to the blockchain, their geographical presence, and company developments related to the market. 
The variables required to apply the model are presented in a disaggregated way in Table 2. Their values were calculated directly using data from BIS Research [40] and other secondary reference sources.

Table 2. Variables used for applying the real options model (source: own elaboration).

\begin{tabular}{ccc}
\hline Variables & Value & Source \\
\hline Project value in year 10 & $V_{10}=\$ 20$ billion & \\
Learning investment & $I_{L}=\$ 1.53683$ billion & \\
Initial investment & $I_{0}=\$ 2.900$ billion & BIS Research (2019) [40] \\
Learning option time horizon & $n=1$ year & \\
Total time horizon & $m=10$ years & 1 year change in S\&P 500 information technology \\
Volatility & $\sigma=8.36 \%$ & index (consulted on 22 July 2019) [41] \\
Risk-free interest rate & $r_{f}=1.79 \%$ & Jnited States 10 year bond (consulted on 15th \\
\end{tabular}

On the other hand, by implementing the data of Table 2, the specific variables concerning the learning option were calculated, as shown below.

- The upper factor of cash-flow fluctuation is $u=e^{\sigma}=1.029$.

- The lower factor of cash-flow fluctuation is $d=\frac{1}{e^{\sigma}}=0.971$.

- The probability of occurrence of the profitable scenario is as follows:

$$
p=\frac{\left(1+r_{f}\right)-d}{u-d}=80.86 \%
$$

- $\quad$ The probability of occurrence of the nonprofitable scenario is $q=1-p=19.14 \%$.

- The increment in the present value of cash flows (calculated from Equation (A1) in Appendix A and considering that the value of $x_{\max }=1.14$, given that the revaluation potential to S\&P 500 equities in 2020 is $14 \%$ [43] (consulted on 16 January 2020)) is as follows:

$$
x=\frac{\alpha \cdot V_{0}+x_{\max } \cdot I_{L}}{\alpha \cdot V_{0}+I_{L}}=1.101 \% .
$$

Once all the information is gathered, the project value with the learning option can be obtained by applying Equation (4). Specifically, given that the investment value is lower than the project value in the nonprofitable scenario (i.e., $I_{L}<d V_{0}$ ), the project value with the learning option is equal to the following:

$$
V(L)_{0}=x V_{0}-I_{T}=\$ 14.004 \text { billion }
$$

As it can be seen in Equation (5), investment in this project is profitable. In order to isolate the learning option value, it is necessary to calculate the difference between the project value with the learning option, $V(L)_{0}$, and the net present value of the project, $N P V_{0}=V_{0}-I_{0}$, as shown in Equation (6).

$$
\text { Learning option value }=V(L)_{0}-N P V_{0}
$$

Thus, Learning option value $=\$ 14.007$ billion $-(\$ 16.749$ billion $-\$ 2.9$ billion $)=\$ 0.155$ billion.

While this project has a high rate of return, (the return on investment is $R O I=\frac{V(L)_{0}-I_{T}}{I_{T}} \cdot 100=215 \%$ ), the strategic value that entails having the real option to learn supposes only $5.5 \%$ of the total investment profit. According to Morreale et al. [11], managers change their mind when the value of the option is higher or when the waiting time is shorter as they recognize the value of waiting. However, the option value from this study's results can be considered low in comparison to the high rate of return. In this sense, exercising the option would only be feasible if it remained virtually the same for a reasonably 
long period of time. In this sense, in Appendix B, it was checked whether the learning option value would remain constant for the entire project lifespan.

\section{Conclusions}

This study focused on examining the suitability of the learning option approach to the investment in blockchain in the aerospace and automotive industry. In order to facilitate the decision-making process, a new mathematical expression, whose implementation allows calculating the value of the project with the learning option within $n$ periods, was developed. By doing so, this paper contributes to the managerial literature regarding the investment of digital technologies in highly uncertain and volatile industries.

This study results show that investment in blockchain is an excellent strategic option in the automotive and aerospace industry. Theoretically, the learning option helps to make decisions in high-uncertainty environments through a conservative investment system. Therefore, its application to the automotive and aerospace industry would be of great interest due to its high complexity. When the project value is not so clearly profitable, managers can make decisions bearing in mind the specific strategic value at each moment and, thus, balance the uncertainty and the risk associated with both the blockchain technology and the industry. Real options provide a guide for the optimal moment for investment at the same time that optimizes future performance. In the automotive and aerospace industry, investment in blockchain technologies is highly profitable, and exercising the learning option adds value to it. Specifically, the real option value represents $5.5 \%$ of the total project value. This is in line with Martzoukos [27] who stated that "the impact of learning actions is much more important for the case of nonprofitable investment options than for very profitable investment options" (p. 321). In this way, in a highly profitable project, such as that analyzed, managers may prefer to invest at the beginning with a consequent fall in the learning option value. As previously mentioned, this percentage increases as the traditional net present value (NPV) of the project decreases. However, for this particular industry, the increase is minimum, which demonstrates that the learning option approach is suitable for assessing this kind of investment, becoming a valid indicator for its incorporation into strategic tools such as the balance scorecard.

This particular behavior usually happens for highly profitable investments such as blockchain technology where it is straightforward that novelty will be lost. Moreover, due to the little development of this technology in the sector and its positive effects, it becomes a profitable option even for companies with a higher risk aversion. These results may be due to the great novelty of this technology associated with a general refusal to adopt it. However, it cannot be thought that this trend will remain stable in the future. That is, there is a foreseeable moment in the future from which the use of the learning option will be decisive for decision-making processes regarding blockchain investment in this sector, even when losing the small relative added value.

Although many contributions have been made in the assessment of investment projects through real options $[2,7,12]$, the investment in digital technologies coming from Industry 4.0 pose new challenges, with a need to reevaluate the suitability of this approach and their strategic implications. The present research is in line with the reports assuring that changes in the aerospace and automotive industry must be done cautiously as the implications can be very significant [23,24]. The main recommendations addressed to managers are essentially based on learning from digital technologies and gradually preparing for the changes. In this sense, the learning option approach represents a more flexible option which allows adaptation to the changing circumstances no matter how small they are, as well as their incorporation into the strategic planning derived from the implementation of digital technology.

Diverse directions can be taken to improve this work. First, it is important to move forward in the study of the sector's casuistry and other particularities to determine other types of effects that can hinder the correct application of the learning option. Secondly, although the learning option was demonstrated to enrich the decision-making process, it might be useful to test the validity of other 
types of real options in order to shed some light on the evolution of the strategic value. Consequently, it would be necessary to determine the modalities of real options that would add greater strategic value given the current technological development in this sector. Thirdly, the use of aggregated data prevented a detailed study of where in the industry's supply chain a learning option would fit better or have greater implications. This would be of great interest because the impact of the implementation of blockchain technology in one part of the supply chain can have a significant impact on other parts, including the supply chain as a whole.

Author Contributions: Methodology, Formal analysis and Investigation, A.M.S.P., J.T.F. and S.C.R.; Writing —Original Draft Preparation, J.T.F. and A.M.S.P.; Writing—Review and Editing, S.C.R., A.M.S.P. and J.T.F. All authors have read and agreed to the published version of the manuscript.

Funding: This research was funded by the Spanish Ministry of Economy and Competitiveness (National R\&D Project "La sostenibilidad del Sistema Nacional de Salud: reformas, estrategias y propuestas", reference: DER2016-76053-R).

Acknowledgments: The authors are very grateful for the comments and suggestions offered by the two anonymous referees.

Conflicts of Interest: The authors declare no conflict of interest.

\section{Appendix A}

The increment in present value of the future cash flows as a consequence of investing in the learning option is calculated as follows:

$$
x=\frac{\alpha \cdot V_{0}+x_{\max } \cdot I_{L}}{\alpha \cdot V_{0}+I_{L}}
$$

where $\alpha=\left(x_{\max }-1\right) \frac{I_{L} \cdot x_{\max }}{V_{0}}$.

The profit derived from learning is a function of the investment in learning $\left(I_{L}\right)$. In this way, $x$ strictly increases with respect to $I_{L}$.

$$
\frac{\mathrm{d} x}{\mathrm{~d} I_{L}}=\frac{x_{\max }-1}{\left(1+I_{0}\right)^{2}}>0
$$

However, this relationship is not linear. In this way, the function shown in Equation (A1) may represent the increment in profits because of the investment in the learning option. By analyzing Equation (A1), it is worth mentioning two special cases:

- when $I_{L}=0 \Rightarrow x=1$, it means that, when there is no investment to learn, the present value of the future cash flows $\left(V_{0}\right)$ does not change.

- when $I_{L}=\infty \Rightarrow x=x_{\max }$, it means that the profits derived from an initial investment in the learning option are not unlimited; there is a maximum value of $x$ beyond which the present value of the future cash flows stops growing.

\section{Appendix B}

In this section, according to data from the BIS Research report [40], it is verified that the project value with the learning option within $k+1$ periods, $V(L)_{0}^{k+1}$, is greater than or equal to the project value with the learning option within $k$ periods, $V(L)_{0}^{k}$; that is,

$$
V(L)_{0}^{k} \leq V(L)_{0}^{k+1},
$$

where $k=1,2,3, \ldots, m$, with $m$ being the project time horizon.

The project value is calculated by applying the project data (detailed in Section 4) to Equation (4). 
Given that, for all values of $k(k=1,2,3 \ldots 10)$, the value of the total investment, $I_{T}$, is lower than the value of the project in the unfavorable scenario, $\frac{d^{n} V_{0}}{\left(1+r_{f}\right)^{n}}$, both at the present moment, i.e.,

$$
I_{T}<\frac{d^{n} V_{0}}{\left(1+r_{f}\right)^{n}}
$$

the project and the option value to every considered learning option time horizon, $k$, is constant (as can be seen in Table A1). Specifically,

$$
V(L)_{0}^{k}=V(L)_{0}^{k+1}=x V_{0}-I_{T} .
$$

In the same way, the learning option value of $k$ is equal to the learning option value of $k+1$ for every considered period.

Table A1. Project value (in billion USD) calculated depending on the learning option time horizon (source: own elaboration).

\begin{tabular}{ccccc}
\hline $\boldsymbol{k}$ & $\boldsymbol{I}_{\boldsymbol{T}}$ & $\frac{d^{n} V_{0}}{\left(1+r_{f}\right)^{n}}$ & $\boldsymbol{V}(\boldsymbol{L})_{0}^{\boldsymbol{k}}($ See Equation (4)) & Learning Option Value (See Equation (4)) \\
\hline 1 & 4.436 & 15.977 & 14.003 & 0.155 \\
2 & 4.436 & 15.241 & 14.003 & 0.155 \\
3 & 4.436 & 14.538 & 14.003 & 0.155 \\
4 & 4.436 & 13.869 & 14.003 & 0.155 \\
5 & 4.436 & 13.229 & 14.003 & 0.155 \\
6 & 4.436 & 12.620 & 14.003 & 0.155 \\
7 & 4.436 & 12.038 & 14.003 & 0.155 \\
8 & 4.436 & 11.484 & 14.003 & 0.155 \\
9 & 4.436 & 10.955 & 14.003 & 0.155 \\
10 & 4.436 & 10.450 & 14.003 & 0.155 \\
\hline
\end{tabular}

\section{References}

1. Trașcă, D.L.; Ștefan, G.M.; Sahlian, D.N.; Hoinaru, R.; Șerban-Oprescu, G.-L. Digitalization and Business Activity. The Struggle to Catch up in CEE Countries. Sustainability 2019, 11, 2204. [CrossRef]

2. Lee, I.; Shin, Y.J. Fintech: Ecosystem, business models, investment decisions, and challenges. Bus. Horiz. 2018, 61, 35-46. [CrossRef]

3. Tarifa-Fernández, J.; Casado-Belmonte, M.P.; Martínez-Romero, M.J. Perspective and Challenges of Blockchain Technology in the Accountability of Financial Information. In Architectures and Frameworks for Developing and Applying Blockchain Technology; IGI Global: Hershey, PA, USA, 2019; pp. 45-68.

4. Nowiński, W.; Kozma, M. How can blockchain technology disrupt the existing business models? Entrep. Bus. Econ. Rev. 2017, 5, 173-188. [CrossRef]

5. Cowan, K.R.; Daim, T.U. Review of technology acquisition and adoption research in the energy sector. Technol. Soc. 2011, 33, 183-199. [CrossRef]

6. Benaroch, M.; Kauffman, R.J. A Case for Using Real Options Pricing Analysis to Evaluate Information Technology Project Investments. Inf. Syst. Res. 1999, 10, 70-86. [CrossRef]

7. Kauffman, R.J.; Li, X. Technology competition and optimal investment timing: A real options perspective. IEEE Trans. Eng. Manag. 2005, 52, 15-29. [CrossRef]

8. McGrath, R.G.; MacMillan, I.C. Assessing technology projects using real options reasoning. Res. Technol. Manag. 2000, 43, 35-49. [CrossRef]

9. Carlsson, C.; Fullér, R. A fuzzy approach to real option valuation. Fuzzy Sets Syst. 2003, 139, $297-312$. [CrossRef]

10. Lander, D.M.; Pinches, G.E. Challenges to the practical implementation of modeling and valuing real options. Q. Rev. Econ. Financ. 1998, 38, 537-567. [CrossRef] 
11. Morreale, A.; Mittone, L.; Vu, T.T.T.; Collan, M. To wait or not to wait? Use of the flexibility to postpone investment decisions in theory and in practice. Sustainability 2020, 12, 3451. [CrossRef]

12. Shi, P.; Yan, B.; Zhao, J. Appropriate timing for SMEs to introduce an Internet-based online channel under uncertain operating costs: A real options analysis. Electron. Commer. Res. 2020, 20, 969-999. [CrossRef]

13. Schneider, R.; Imai, J. Valuing Investments in Digital Transformation of Business Models. Int. J. Real Options Strategy 2019, 7, 1-26. [CrossRef]

14. Attaran, M.; Gunasekaran, A. Blockchain-enabled technology: The emerging technology set to reshape and decentralise many industries. Int. J. Appl. Decis. Sci. 2019, 12, 424-444. [CrossRef]

15. Favato, G.; Vecchiato, R. Embedding real options in scenario planning: A new methodological approach. Technol. Forecast. Soc. Chang. 2017, 124, 135-149. [CrossRef]

16. Rimba, P.; Tran, A.B.; Weber, I.; Staples, M.; Ponomarev, A.; Xu, X. Comparing Blockchain and Cloud Services for Business Process Execution. In Proceedings of the 2017 IEEE International Conference on Software Architecture, Gothenburg, Sweden, 3-7 April 2017; Institute of Electrical and Electronics Engineers Inc.: Piscataway, NJ, USA, 2017; pp. 257-260.

17. Viriyasitavat, W.; Da Xu, L.; Bi, Z.; Sapsomboon, A. Blockchain-based business process management (BPM) framework for service composition in industry 4.0. J. Intell. Manuf. 2020, 31, 1737-1748. [CrossRef]

18. Konstantinidis, I.; Siaminos, G.; Timplalexis, C.; Zervas, P.; Peristeras, V.; Decker, S. Blockchain for business applications: A systematic literature review. In The Lecture Notes in Business Information Processing; Springer: Cham, Switzerland, 2018; Volume 320, pp. 384-399.

19. Wang, J.; Wu, P.; Wang, X.; Shou, W. The outlook of blockchain technology for construction engineering management. Front. Eng. Manag. 2017, 4, 67. [CrossRef]

20. Subramanian, N.; Chaudhuri, A.; Kayıkc1, Y.; Subramanian, N.; Chaudhuri, A.; Kayıkc1, Y. Information System Evolution and Blockchain. In Blockchain and Supply Chain Logistics; Springer: Cham, Switzerland, 2020; pp. 1-9.

21. Association, A.I. Blockchain in Aerospace and Defense. Establishing an Industry Approach to Blockchain Governance, Standards, and Participation; Aerospace Industries Association: Arlington, VA, USA, 2019.

22. Schmidt, J.; Gelle, M.; Gottlieb, C. Driving Trust: Distributed Ledger for Supply Chain; Accenture Consulting: Chicago, IL, USA, 2020.

23. Aaronson, M.; Caffrey, H.; Won, S.; Ahlquist, J. Getting Real about Blockchain in Aerospace and Defence; The Boston Consulting Group: Boston, MA, USA, 2018.

24. Consulting, A. Blockchain in Aerospace and Defense. Capturing Growth and Efficiency through a Rapidly Emerging Technology; Accenture Consulting: Chicago, IL, USA, 2017.

25. Gilain, A.; Le Masson, P.; Weil, B. The hidden feat behind development cost escalation-How engineering design enables functional expansion in the aerospace industry. In Proceedings of the International Conference on Engineering Design, ICED; Cambridge University Press: Cambridge, UK, 2019; Volume 1, pp. 3011-3020.

26. Adner, R.; Levinthal, D.A. What Is Not a Real Option: Considering Boundaries for the Application of Real Options to Business Strategy. Acad. Manag. Rev. 2004, 29, 74. [CrossRef]

27. Martzoukos, S.H. Real Options with Random Controls and the Value of Learning. Ann. Oper. Res. 2000, 99, 305-323. [CrossRef]

28. McCardle, K.F. Information Acquisition and the Adoption of New Technology. Manag. Sci. 1985, 31, $1372-1389$. [CrossRef]

29. Goswami, S.; Teo, H.; Chan, H. Real options from RFID adoption: The role of institutions and managerial mindfulness. In Proceedings of the International Conference on Information Systems, ICIS 2008, Paris, France, 14-17 December 2008.

30. Krychowski, C.; Quelin, B. How Can Real Options Help Define Optimal Timing in Business Model Dynamics? An Application to the Mobile Telecommunications Industry. 2014. Available online: https://www.strategie-aims.com/events/conferences/24-xxiiieme-conference-de-1-aims/communications/ 3276-how-can-real-options-help-define-optimal-timing-in-business-model-dynamics-an-application-tothe-mobile-telecommunications-industry/download (accessed on 12 September 2020).

31. Copeland, T.E.; Keenan, P.T. Making real options real. McKinsey Q. 1998, 3, 128-141.

32. Turvey, C.G. Mycogen as a Case Study in Real Options. Rev. Agric. Econ. 2001, 23, 243-264. [CrossRef]

33. Childs, P.D.; Triantis, A.J. Dynamic R\&D investment policies. Manag. Sci. 1999, 45, 1359-1377.

34. Brach, M. Real Options in Practice; John Wiley \& Sons, Inc.: Hoboken, NJ, USA, 2003. 
35. Plaza Gonzalez, C.; Sánchez Pérez, A.M. Opciones reales para la valoración del proceso de internacionalización de Mercadona. In XX Reunión de Economía Mundial; Editorial Universidad de Almería: Almería, Spain, 2018.

36. Cruz Rambaud, S.; Sanchez Perez, A.M. An assessment of the option to reduce the investment in a project by the binomial pricing model. Eng. Econ. 2017, 28, 514-523. [CrossRef]

37. Sarkar, S. On the investment-uncertainty relationship in a real options model. J. Econ. Dyn. Control 2000, 24, 219-225. [CrossRef]

38. Dikos, G. Real options econometrics for aggregate tanker investment decisions. Int. J. Ocean Syst. Manag. 2008, 1, 31-44. [CrossRef]

39. Sahaym, A.; Treviño, L.J.; Steensma, H.K. The influence of managerial discretion, innovation and uncertainty on export intensity: A real options perspective. Int. Bus. Rev. 2012, 21, 1131-1147. [CrossRef]

40. Research, B. Blockchain in Automotive and Aerospace \& Aviation Market: Focus on Key Application and Types of Blockchain-Analysis and Forecast, 2019-2029. 2019. Available online: https://www.prnewswire.com/news-releases/blockchain-in-automotive-and-aerospace--aviation-marketfocus-on-key-application-and-types-of-blockchain--analysis-and-forecast-2019-2029-300867422.html (accessed on 10 January 2020).

41. Dow Jones Today|DJIA Index Live-Investing.com. Available online: https://www.investing.com/indices/us30 (accessed on 22 July 2020).

42. Daily Treasury Yield Curve Rates. Available online: https://www.treasury.gov/resource-center/data-chartcenter/interest-rates/pages/TextView.aspx?data=yieldYear\&year=2020 (accessed on 15 January 2020).

43. Previsión S\&P 500 Para 2020|Blog Bankinter. Available online: https://www.bankinter.com/blog/mercados/ prevision-sp500 (accessed on 16 January 2020).

Publisher's Note: MDPI stays neutral with regard to jurisdictional claims in published maps and institutional affiliations. 